
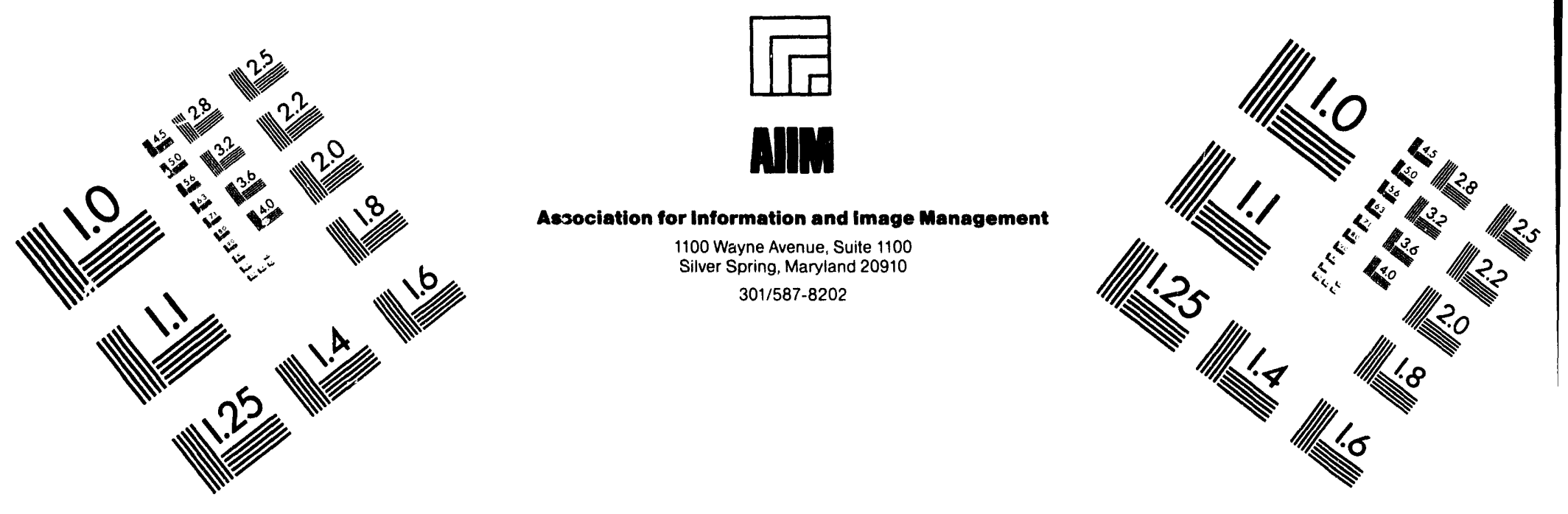

\title{
Centimeter
}

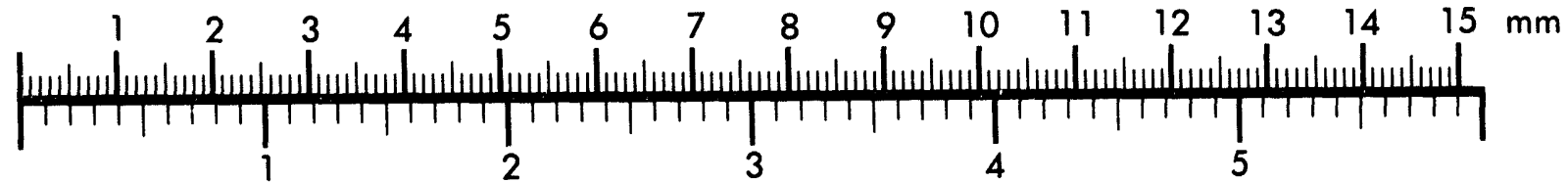
Inches
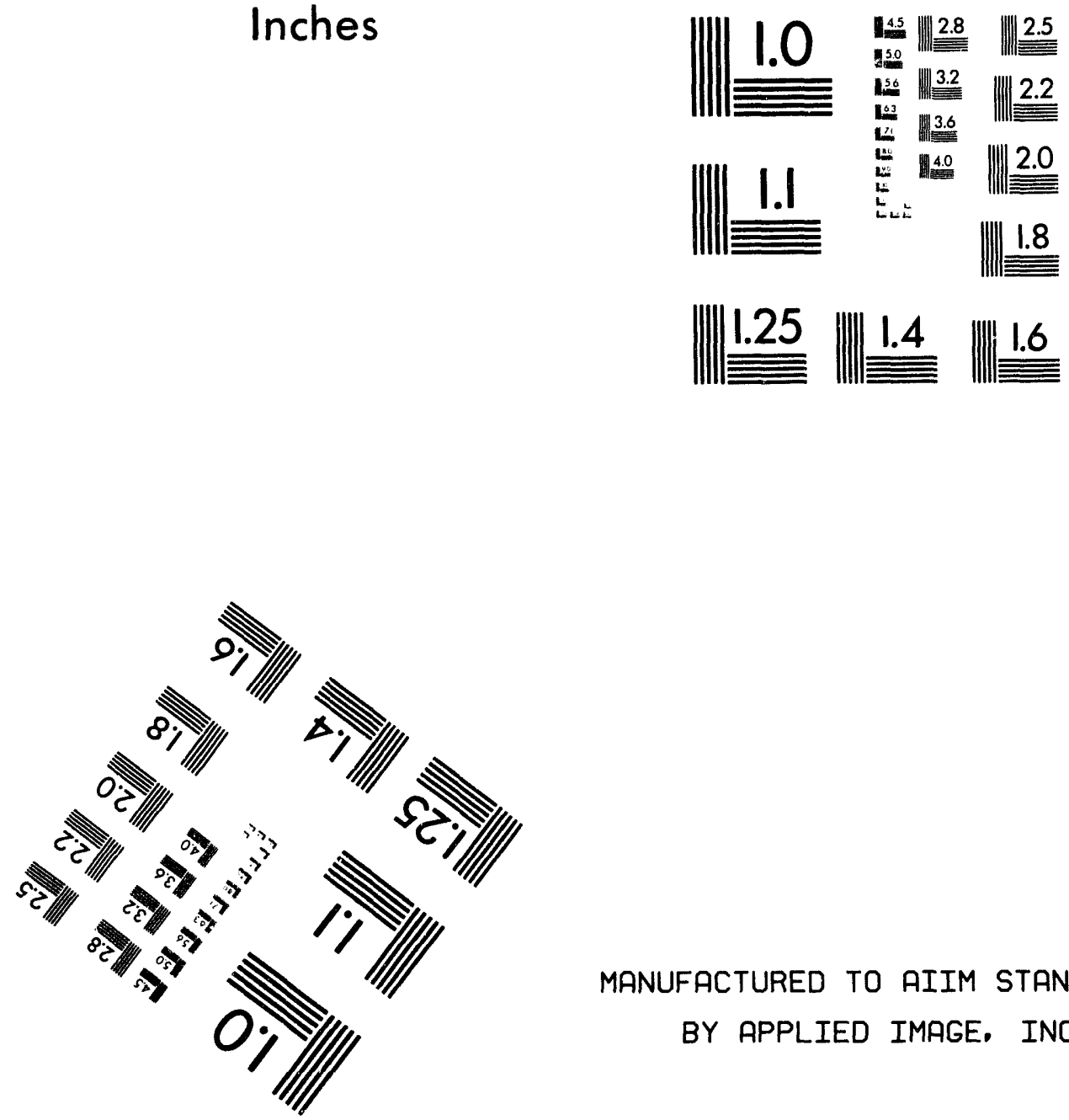

MANUFACTURED TO AIIM STANDARDS BY APPLIED IMAGE. INC.

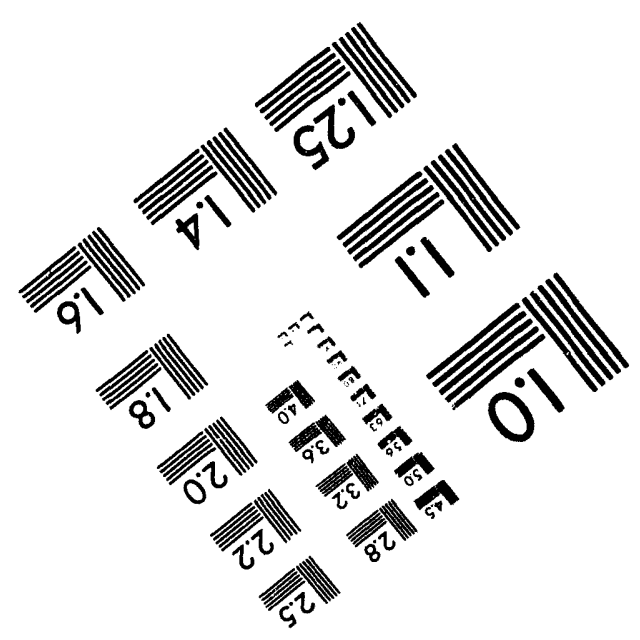



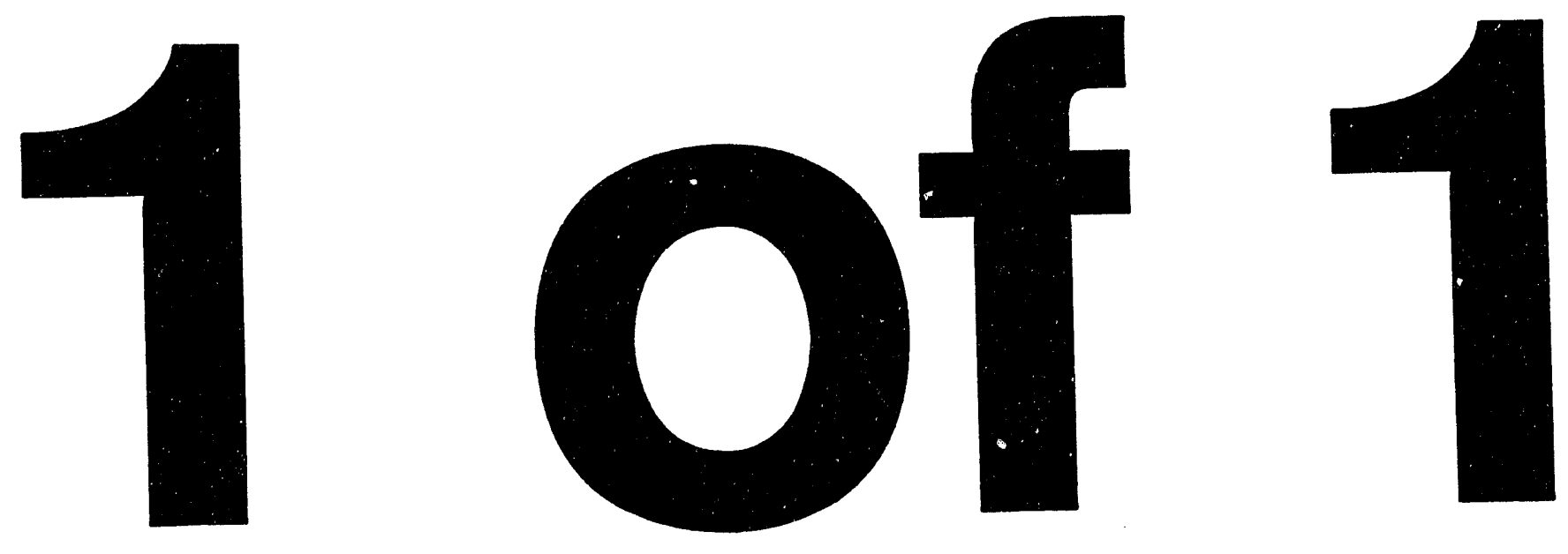
$\mathrm{DOE} / \mathrm{ER} / 13778-62$

CORRELATED CHARGE-CHANGING ION-ATOM COLLISIONS

PROGRESS REPORT

FOR THE PERIOD FEBRUARY 16, 1993 - APRIL 15, 1994

J. A. TANIS

PRINCIPAL INVESTIGATOR

\author{
WESTERN MICHIGAN UNIVERSITY \\ KALAMAZOO, MICHIGAN 49008
}

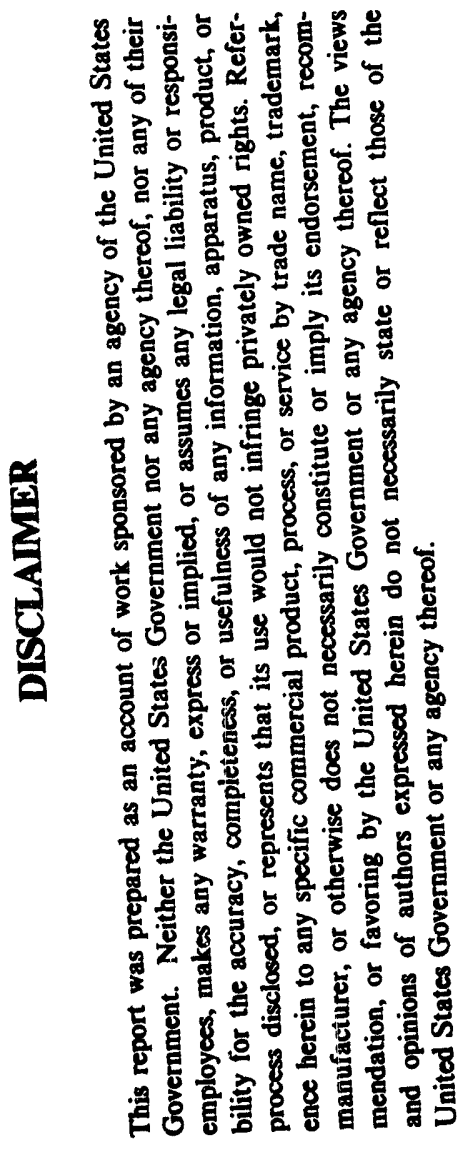

APRIL 1994

PREPARED FOR

THE U.S. DEPARTMENT OF ENERGY

OFFICE OF ENERGY RESEARCH

OFFICE OF BASIC ENERGY SCIENCES

DIVISION OF CHEMICAL SCIENCES

GRANT NO. DE-FG02-87ER13778.A006

\title{
Mester
}


TABLE OF CONTENTS

PAGE

I. RESEARCH PROGRESS

II. PERSONNEL 16

III. PUBLICATIONS AND PRESENTATIONS 


\section{RESEARCH PROGRESS}

This report summarizes the progress and accomplishments of research supported by DOE grant DE-FG02-87ER13778.A006 from February 16, 1993 through April 15, 1994. This work involves the experimental investigation of fundamental atomic processes in collisions of few-electron, charged projectile ions with neutral gas targets or electrons. The major emphasis is the study of collision processes involving two active electrons, and particularly those in which the electron-electron interaction plays a role. New results have been obtained for studies involving (1) continuum-electron emission, (2) double ionization of helium and $\mathrm{Li}^{+}$, and (3) resonant recombination of atomic ions. Experiments were conducted using accelerators at Western Michigan University, Michigan state University, Indiana University, Lawrence Livermore Laboratory, and the Institute of Nuclear Research, Debrecen, Hungary. Brief summaries of work completed and work in progress are given immediately below:

\section{Mechanisms of Cusp-Electron Production}

The emission of continuum electrons along the beam direction, i.e., at $0^{\circ}$, and traveling with the velocity of the beam (so-called "cusp electrons") is a problem of fundamental interest. In addition to the direct emission of such electrons, cusp electrons may be accompanied by the capture or loss of a second active electron. Primary objectives of this work are to determine the mechanisms responsible for cusp-electron production and to evaluate the role of the electron-electron interaction.

1. Cusp-electron production in intermediate-energy $07++\mathrm{Ar}$ collisions.--In work done at Western Michigan University, cusp-electron production has been investigated for $0.5-1.5 \mathrm{MeV} / \mathrm{u} 0^{7+}$ ions colliding with $\mathrm{Ar}$. For this system, cusp electrons can result from electron capture or loss to the continuum (ECC or ELC), transfer ionization (TI), or double transfer ionization (2TI). Of particular interest are the two- and three-electron processes TI and 2TI. Electrons emitted at $0^{\circ}$ were detected in coincidence with $0^{7+}, 0^{8+}, 0^{6+}$, and $\mathrm{O}^{5+}$, to identify ECC, ELC, TI, and $2 \mathrm{TI}$, respectively. The ratios TI/ECC and $2 T I / E C C$, which represent the probabilities for cusp-electron production as part of multi-electron processes compared to the single-electron process, each exhibit a maximum near $0.75 \mathrm{MeV} / \mathrm{u}$, while the ELC/ECC ratio increases monotonically with beam energy. The reasons for these behaviors, including possible electron correlation, are currently being investigated.

2. Oriqin of cusp electrons in intermediate-energy $\mathrm{H} \pm+\mathrm{Ar}$ collisions. - Cusp electrons associated with bound-state capture (TI) have been investigated in 33-75 keV/u H$H^{+}+$Ar collisions. This work, which is an extension of our previous work for $\mathrm{He}^{+}$ions, was done at the Institute of Nuclear Research, Debrecen, Hungary. The present case is of particular importance because information for $\mathrm{H}^{+}$, as the simplest projectile, is needed to determine the scaling properties of TI. A fuxther motivation for using $\mathrm{H}^{+}$projectiles is to determine whether cusp-electron production leading to a neutral particle in the final state (i.e., TI) is produced via a direct or an exchange mechanism. Salin ${ }^{1}$ recently suggested that $T I$ could come about by means of an exchange mechanism involving a two-step process in which a cusp electron is produced via ELC followed by a double-capture event. For incident $\mathrm{H}^{+}$(or any bare projectile) only the direct process is possible. Analysis of our results is 
currently underway to determine if the direct or exchange mechanism is responsible for TI in the present measurements.

\section{Double Ionization at Intermediate- to High-Velocities}

Double ionization by intermediate- to high-velocity charged ions is attributed to two mechanisms: (a) a two-step (TS) process in which both electrons are removed in separate direct interactions with the projectile, and (b) a one-step mechanism in which one electron is liberated in a single projectile-target interaction followed by subsequent "shakeoff" (SO) of the second electron due to electron correlation. From various studies, it can be inferred that the two-step (TS) mechanism dominates for projectile charges $q$ and velocities $\mathrm{v}$ (in atomic units) such that $\mathrm{q} / \mathrm{v}>0.2$, while shakeoff (SO) dominates for $\mathrm{q} / \mathrm{v}<0.05$. Both $\mathrm{TS}$ and so are likely to be important in the intermediate range $0.2 \geq \mathrm{q} / \mathrm{v} \geq 0.05$. New studies include:

1. Ionization of Li \pm in collisions with $\mathrm{H}_{2}$ and He.-Double and single ionization of $\mathrm{Li}^{+}$was studied for $0.5-7 \mathrm{MeV} \mathrm{Li}^{+}$ions colliding with $\mathrm{H}_{2}$ and $\mathrm{He}$ in work done at WMU. By considering the $\mathrm{H}_{2}$ target to be two protons and $\mathrm{He}$ to be $\mathrm{He}^{2+}$, ionization of two-electron $\mathrm{Li}^{+}$can be compared with ionization of two-electron He. Qualitatively, single and double ionization of $\mathrm{Li}^{+}$is expected to be similar to ionization of He. Specifically, for the intermediate-velocity regime explored here, double ionization is expected to occur mainly via the TS mechanism and exhibit only a tendency towards the so mechanism at the highest velocities investigated. Indeed, the double-tosingle ionization ratios, i.e., $\mathrm{Li}^{3+} / \mathrm{Li}^{2+}$, show reasonable agreement with the scaling of knudsen et al. ${ }^{2}$ in its region of validity, with the ratios tending toward an asymptotic value at the highest velocities. In this latter regard, Dalgarno and Sadeghpour ${ }^{3}$ have predicted the asymptotic value of the double-tosingle photoionization ratio for $\mathrm{Li}^{+}$to be $\sim 0.5$ times that for He.

2. Ionization of helium by Het projectiles.- - A reevaluation was conducted of our previous data for the single and double ionization of helium by 0.125-3.0 $\mathrm{MeV} / \mathrm{u} \mathrm{He}^{+}$ions (measurements done at WMU). In this work, ionization was measured for different ranges of impact parameters by associating target ionization with projectiles undergoing electron capture, loss, or no charge change. By comparing the resulting double-to-single ionization ratios to those obtained for bare ions, the contribution of the projectile electrons to double ionization could be determined. The reevaluation of our data has led to a more complete understarding of the observed single and double ionization within the framework of existing theories, and a revised manuscript has been submitted for publication.

\section{Resonant Recombination}

Resonant recombination of an atomic ion occurs when electron capture (transfer) is accompanied by simultaneous excitation, resulting in the formation of an intermediate doubly- (or multiply-) excited state, followed by subsequent radiative stabilization. The formation of the intermediate state is mediated by the electron-electron interaction, and is resonant for relative velocities equal to corresponding Auger-electron velocities. In an ion-atom collision, resonant recombination is referred to as resonant transfer excitation (RTE), while in electron-ion collisions it is called dielectronic recombination (DR). Three new studies have been conducted. 
1. Recombination in $\mathrm{Kr}^{34+}+\mathrm{H}_{2}$ collisions.--Three mechanisms leading to recombination have been investigated in high-energy $\mathrm{Kr}^{34+}+\mathrm{H}_{2}$ collisions. The measurements were conducted using the K1200 cyclotron at Michigan state University. Resonant transfer excitation (RTE) was measured in the range 15.5-18.2 MeV/u, while radiative electron capture (REC) and resonant transfer double excitation (RT2E) were studied for $37.2-47.5 \mathrm{MeV} / \mathrm{u}$ incident ions. RTE and REC (inverse photoelectric effect) have been studied extensively, while RT2E has not. This latter process is a three-electron correlation mechanism in which electron capture is accompanied by simultaneous excitation of two electrons to form an intermediate excited state. Data were collected by detecting coincidences between electron capture events and $x$-ray emission. Measurements for RTE involving KLL transitions and for REC to the $L$ and $M$ shells are in reasonable agreement with theory. Electron capture/x-ray coincidences for RT2E were not observed; comparisons with theory are being made to determine an upper limit to the RT2E cross section.

2. Dielectronic recombination for $\mathrm{Li} \pm$ ions.--DR was investigated for $\mathrm{Li}^{+}\left(1 \mathrm{~s}^{2}\right)$ $+e^{-} \rightarrow\left[\mathrm{Li}^{\circ}\left(1 \mathrm{snln} \mathrm{I}^{\prime} \mathrm{I}^{\prime}\right]^{* *}\right.$ using the electron cooler at the Indiana University Cyclotron Facility (IUCF). For $\mathrm{Li}^{+}\left(1 \mathrm{~s}^{2}\right)$ ions, DR is expected to occur for relative energies $E_{\text {rel }}$ of $50-60 \mathrm{eV}$ between the ion and the electron. However, the metastable beam component $\mathrm{Li}^{+}(1 \mathrm{~s} 2 \mathrm{~s})$ can give rise to $\mathrm{DR}$ involving $2 \mathrm{~s}-->2 \mathrm{p}$ transitions for relative energies near zero. Also, for $\mathrm{E}_{\text {rel }}=0$, a peak due to radiative recombination ( $R R$ ) (inverse photoelectric effect) is expected. The present work is an extension of our previous work at IUCF for $\mathrm{He}^{+}$ions. These light $\mathrm{He}^{+}$and $\mathrm{Li}^{+}$ions pose stringent tests of $\mathrm{DR}$ theory because the electronelectron interaction, which mediates $D R$, is stronger compared to electronnucleus interactions than it is for heavier ions. Additionally, the electron coupling in two-electron $\mathrm{Li}^{+}$gives rise to angular momentum configurations different from those in $\mathrm{He}^{+}$. In recent measurements at IUCF, we did observe $\mathrm{DR}$ for $\mathrm{Li}^{+}$, but the beam intensity was too low and the beam stability too erratic to give good results. There also was an indication of a significant $D R$ contribution near zero relative energy resulting from metastable $\mathrm{Li}^{+}$(1s2s) ions. Additional measurements with better beam conditions are planned.

3. Dielectronic recombination in U $89,90+$ ions.--DR involving excitation via KLM, KLN, KMM,... transitions was investigated for highly-charged $\mathrm{U}^{89,90+}$ ions using the electron beam ion trap (EBIT) at Lawrence Livermore Laboratory (LLNL). This work complements earlier work 4 at LLNL investigating DR via KLL transitions for these same ions. In the present work, the electron energy was ramped relative to the ion energy over the range 75-100 kev, and $x$-ray emission resulting from decay of the intermediate excited state was recorded as a function of the electron energy. Thus, radiative recombination was also observed. These measurements were just recently completed (March 1994) and analysis is underway.

\section{REFERENCES}

1. A. Salin, unpublished, 1993.

2. H. Knudsen et al., J. Phys. B17, 3545 (1984).

3. A. Dalgarno and H. R. Sadeghpour, Phys. Rev. A46, R3591 (1992).

4. D. Knapp et al., submitted to Phys. Rev. Lett. 


\section{PERSONNEL}

A. Principal Investigator

John A. Tanis

- Professor, Department of Physics

B. Professional Research Staff

Dr. Roger $R$. Haar

- Research Associate

Dr. Stephen M. Ferguson

- Accelerator Physicist

C. Technical support staff
Mr. Robert Hiltbrand
- Electronics Technician
Mr. Tyrone Bynum
- Electronics Technician
Mr. James Cornell
- Instrument Maker

D. Graduate students
Ms. Vicki Plano
- Ph.D. (left WMU September 1993)
Mr. Oliver Woitke
- Ph.D.
Mr. Konstantin Zaharakis - Ph.D.
Mr. Ming Zhu
- Ph.D.

E. Undergraduate students

Ms. Layle Griffioen

Ms. Erica Jasper 


\section{PUBLICATIONS AND PRESENTATIONS}

\section{Publications}

1. "Measurement of Dielectronic Recombination in He ${ }^{+}$Ions," R. R. Haar, J. A. Tanis, V. L. Plano, K. E. Zaharakis, W. G. Graham, J. R. Mowat, T. Ellison, W. W. Jacobs, and T. Rinckel, Phys. Rev. A $\underline{47}$, R3472 (1993); (Rapid Comm.).

2. "Low-Energy Continuum-Electron Emission at $0^{\circ}$ from $0^{+}+$He Collisions," J. A. Tanis, R. R. Haar, D. Schneider, M. W. Clark, M. H. Prior, R. D. DuBois, and K. Randall, AIP Conference proceedings 274, P. Richard, $M$. Stöckli, C. L. Cocke, and C. D. Lin eds., (American Institute of physics, New York, 1993), pp. 210-213.

3. "Testing Double Ionization Mechanisms with Highly-Charged Ions," J. A. Tanis, AIP Conference proceedings 274, P. Richard, M. Stöckli, C. L. Cocke, and C. D. Lin eds., (American Institute of Physics, New York, 1993), pp. 262-270.

4. "Search for Resonant Electron Transfer and Double Excitation in $\mathrm{Kr}^{34+}+$ $\mathrm{H}_{2}$ Collisions," K. E. Zaharakis, R. R. Haar, J. A. Tanis, M. W. Clark, and V. L. Plano, AIP Conference proceedings 274, P. Richard, M. Stöckli, C. L. Cocke, and C. D. Lin eds., (American Institute of Physics, New York, 1993), pp. 303-306.

5. "Cusp Electron Production in 75-300 keV He+ + Ar Collisions," V. L. Plano, L. Sarkadi, P. Závodszky, D. Berényi, J. Pálinkás, L Gulyás, E. Takács, L. Tóth, and J. A. Tanis, AIP Conference proceedings 274, P. Richard, M. Stöckli, C. L. Cocke, and C. D. Lin eds., (American Institute of Physics, New York, 1993), pp. 307-310.

6. "Projectile Energy Dependence of the Contributions of Different Mechanisms to Cusp Electron Production in $\mathrm{He}^{+}+\mathrm{Ar}$ Collisions," P. A. Závodszky, L. Sarkadi, J. A. Tanis, D. Berényi, J. Pálinkás, V. I. Plano, L. Gulyás, E. Takács, and L. Tóth, Nucl. Instrum. Meth. Phys. Res. B79, 67 (1993).

\section{Publications - in press}

1. "Production of Low-Energy Continuum Electrons at $0^{\circ}$ by $4.4 \mathrm{keV} / \mathrm{u} \mathrm{O}^{8+}$ Ions," V. L. Plano, R. R. Haar, J. A. Tanis, J. Pálinkás, L. Sarkadi, P. A. Závodszky, D. Berényi, H. Khemliche, M. H. Prior, and D. Schneider, Nucl. Instrum. Meth. Phys. Res. B, in press.

\section{Publications - submitted}

1. "Single and Double Ionization of Helium by Intermediate-to-High Velocity $\mathrm{He}^{+}$Projectiles," J. L. Forest, J. A. Tanis, S. M. Ferguson, R. R. Haar, K. Lifrieri, and V. L. Plano, Phys. Rev. A. 
2. "Comment on 'High-Velocity Limit for the Ratio of Helium Double-to-single Ionization for Highly Charged, Bare-Ion Impact, " A. S. Schlachter and J.

A. Tanis, Phys. Rev. Lett.

\section{Invited Presentations}

1. "Correlated Charge-Changing Ion-Atom Collisions," XIV DOE Atomic Physics program Workshop, Charlottesville, Virginia, 15-16 October 1993, Program and Abstracts.

2. "Atomic Physics with Accelerators," Physics Colloquium, Central Michigan University, Mount Pleasant, Michigan, 23 september 1993.

3. "Electron-Electron Interactions in Ion-Atom Collisions," Atomic and Molecular Physics Research Division Seminar, Queen's University of Belfast, Belfast, Northern Ireland, 18 February 1994.

\section{Contributed Presentations}

1. "Measurement of Dielectronic Recombination in $\mathrm{He}^{+}$Ions," R. R. Haar, V. L. Plano, J. A. Tanis, K. E. Zaharakis, W. G. Graham, J. R. Mowat, T. Ellison, W. W. Jacobs, and T. Rinckel, Division of Atomic, Molecular, and optical Physics Meeting of the American Physical Society, Reno, Nevada, May 1993; Bull. Am. Phys. Soc. 38, 1116 (1993).

2. "Low-Energy Electrons from Multiple-Electron Transfer to slow $0^{8+}$ Ions," H. Khemliche, M. H. Prior, V. L. Plano, R. R. Haar, J. A. Tanis, P. A. Závodszky, L. Sarkadi, J. Pálinkás, and D. Berényi, Division of Atomic, Molecular, and Optical Physics Meeting of the American Physical Society, Reno, Nevada, May 1993; Bull. Am. Phys. Soc. 38,1160 (1993).

3. "The Role of Transfer Ionization in the Emission of Cusp Electrons by Impact of Low-Energy protons on Ar," L. Sarkadi, P. A. Závodszky, J. A. Tanis, M. Kuzel, L. Víkor, M. Zhu, D. Berényi, J. Pálinkás, and K. 0. Groeneveld, Sixteenth International Conference on X-Ray and Inner-Shell processes $(x-193)$, Debrecen, Hungary, July 1993, Abstracts, L. Sarkadi and D. Berényi eds., pp. 159-160.

4. "Production of Low-Energy Continuum Electrons at $0^{\circ}$ by $4.4 \mathrm{keV} / \mathrm{u} \mathrm{O} \mathrm{O}^{8+}$ Ions," V. L. Plano, R. R. Haar, J. A. Tanis, J. Pálinkás, L. Sarkadi, P. Závodszky, D. Berényi, H. Khemliche, M. H. Prior, and D. Schneider, $\underline{5 t h}$ Workshop on Fast Ion-Atom Collision Processes, Debrecen, Hungary, July 1993, Abstracts.

5. "Dielectronic Recombination in $\mathrm{He}^{+}$Ions," R. R. Haar, J. A. Tanis, V. L. Plano, K. Zaharakis, W. G. Graham, J. R. Mowat, T. Ellison, W. W. Jacobs, and $T$. Rinckel, XVIII International Conference on the Physics of Electronic and Atomic Collisions, Aarhus, Denmark, July 1993, Abstracts of Contributed Papers, T. Andersen, B. Fastrup, F. Folkmann, and H. Knudsen eds., p. 378.

6. "Target Z-Dependence of Nonresonant Transfer Excitation (NTE) for $\mathrm{S}^{13+}$ Ions," L. Duo, R. R. Haar, B. Carroll, K. Zaharakis, and J. A. Tanis, XVIII International Conference on the Physics of Electronic and Atomic 
Collisions, Aarhus, Denmark, July 1993, Abstracts of Contributed Papers, T. Andersen, B. Fastrup, F. Folkmann, and H. Knudsen eds., p. 497.

7. "Electron Capture and Loss Cross Sections for Collisions of GeV $\mathrm{U}^{89+}$ and $\mathrm{U}^{90+}$ Projectiles with Light Targets," W. G. Graham, K. H. Berkner, E. M. Bernstein, M. W. Clark, H. Crawford, B. Feinberg, I. Flores, L. Greiner, M. A. McMahan, R. J. McDonald, P. M. Mokler, T. J. Morgan, W. Rathbun, A. S. Schlachter, and J. A. Tanis, XVIII International Conference on the Physics of Electronic and Atomic Collisions, Aarhus, Denmark, July 1993, Abstracts of Contributed Papers, T. Andersen, B. Fastrup, F. Folkmann, and H. Knudsen eds., p. 609.

8. "Production of Low-Energy Electrons by $80 \mathrm{keV} 0^{8+}$ Ions," V. L. Plano, R. R. Haar, J. A. Tanis, L. Sarkadi, P. A. Závodszky, J. Pálinkás, D. Berényi, M. H. Prior, H. Khemliche, and D. Schneider, XVIII International Conference on the Physics of Electronic and Atomic Collisions, Aarhus, Denmark, July 1993, Abstracts of Contributed Papers, T. Andersen, B. Fastrup, F. Folkmann, and H. Knudsen eds., p. 624. 

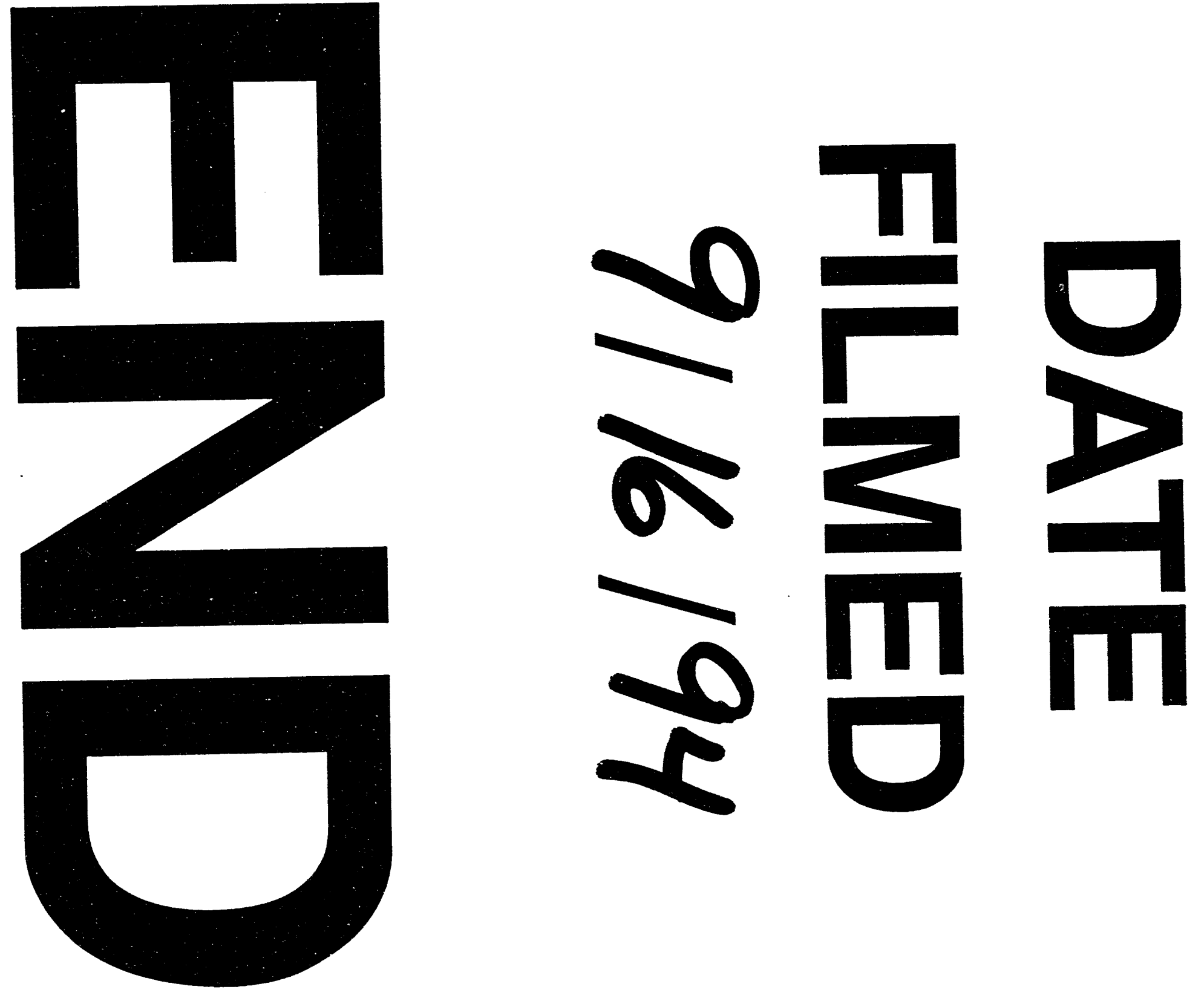
